\title{
Reducing Raw Emissions from a Gasoline Direct Injection Engine via Sensor-aware Diluted Combustion
}

\author{
Juan Yan, ${ }^{1,2}$ Le Gao, ${ }^{3}$ Nina Dai, ${ }^{3 *}$ Li Cai, ${ }^{3}$ \\ Jialan Shi, ${ }^{3}$ Qingshan $\mathrm{Xu},{ }^{4}$ and Christopher Chun Ki Chan ${ }^{5^{* *}}$ \\ ${ }^{1}$ School of Mechanical Engineering, Chongqing Three Gorges University, Chongqing 404000, China \\ ${ }^{2}$ Chongqing Engineering Technology Research Center for Light Alloy and Processing, Chongqing 404000, China \\ ${ }^{3}$ Signal and Information Processing Key Laboratory, Chongqing Three Gorges University, \\ Chongqing 404000, China \\ ${ }^{4}$ School of Electrical Engineering, Southeast University, Nanjing 211189, China \\ ${ }^{5}$ Department of Information Management, Chaoyang University of Technology, Taichung 413, Taiwan
}

(Received October 21, 2020; accepted March 10, 2021)

Keywords: diluted combustion, engine performance, power structure, emissions, environmental pollution

Environmental pollution caused by vehicles' emissions has been one of the main contributions to climate change, a problem that has attracted significant global attention. Vehicles with diluted combustion engines and electric vehicles are both significant elements in the reduction of environmental pollution. To reduce environmental pollution from vehicle emissions, new vehicle technologies that optimize energy are being developed. One such technology is a sensor-aware exhaust gas recirculation (EGR) system, which measures excess air from diluted combustion engines. We performed experiments on a $1.5 \mathrm{~L}$ four-cylinder direct-injection turbocharged gasoline engine and compared the engine's economic and emission characteristics with those of a combustion engine. The variation law of the influence of different diluted combustion technologies was applied to analyze engine performance. Results show that pollution levels from the two new diluted combustion technologies examined in our study are less than that of the original engine.

\section{Introduction}

With the increasingly high demand for energy and increasing air pollution, the Chinese government has imposed stringent policies and emissions regulations to improve the environment. As a result, energy conservation technologies, innovative internal combustion engine systems, and electric vehicles have been the focus of many research projects in the hope of reducing China's environmental pollution. ${ }^{(1-3)}$ In contrast to a gasoline direct injection (GDI) engine, a vehicle with an electric engine yields zero emissions. However, at present, $70 \%$ of China's electricity comes from thermal power generation, which contributes to China's environmental pollution. ${ }^{(4,5)}$ Adopting diluted combustion technologies for gasoline engines is a better alternative than conventional combustion engines because of their thermal efficiency and

\footnotetext{
*Corresponding author: e-mail: Y406591408@outlook.com

** Corresponding author: e-mail: christopherckchan@cyut.edu.tw

https://doi.org/10.18494/SAM.2021.3182
}

ISSN 0914-4935 ㄷ MYU K.K. https://myukk.org/ 
reduced emissions. ${ }^{(6,7)}$ In China, because of the prevalence of thermal power, the pollution resulting from electric vehicles is greater than that of fuel vehicles with lean combustion technology. There are currently two popular diluted combustion methods: excess air diluted combustion and exhaust gas recirculation (EGR) diluted combustion. ${ }^{\left({ }^{8}\right)}$ These two combustion modes control the difference in the air intake and exhaust using intelligent sensors, and these systems adjust the emissions output after combustion occurs. EGR diluted combustion utilizes the vehicle's exhaust to reduce the rate of combustion and optimizes the combustion phase based on excess air with a coefficient of 1, which reduces gas loss during pumping. ${ }^{(9,10)}$ Excess air diluted combustion increases the proportion of air in the combustion mixture, which increases the polytropic exponent in the engine cylinders, thereby improving overall fuel economy. ${ }^{(1)}$

Many domestic and international research institutes and companies have conducted in-depth research on two kinds of lean-burn technology. Experiments and simulations have been carried out to study the fuel economy of turbocharged gasoline engines that use EGR diluted combustion technology. The analysis revealed that EGR diluted combustion inhibits nitride emissions, thus reducing environmental pollution output. ${ }^{(12)}$ The research on excess air diluted combustion showed that by increasing the air-to-fuel ratio and the polytropic exponent, certain components are affected, such as the throttle's regulated load control, leading to reduced pump loss. ${ }^{(13,14)}$ These aspects greatly improve the thermal efficiency of engines and reduce emissions. ${ }^{(15,16)}$

However, there is still relatively little comparative data of these two diluted combustion technologies for a specific engine. We studied these two diluted combustion modes and compared their environmental pollution with that of electric vehicles. Experiments on EGR diluted combustion and excess air diluted combustion were carried out on a $1.5 \mathrm{~L}$ four-cylinder direct injection turbocharged gasoline engine. Our experiments provided conclusive results, and this study is a significant milestone in providing generic reference data involving environmental pollution caused by thermal power generation for electric vehicles.

\section{Test System and Test Conditions}

\subsection{Test engine and test system}

We used a $1.5 \mathrm{~L}$ direct-injection gasoline engine whose basic parameters are shown in Table 1. The primary test devices included an AVL PUMA system, an Inca engine bench

Table 1

Main technical parameters of the engine.

\begin{tabular}{lc}
\hline Structure and technical parameters & Index \\
\hline Form & In-line four cylinder \\
Engine displacement $(\mathrm{L})$ & 1.497 \\
Bore $\times$ stroke $(\mathrm{mm} \times \mathrm{mm})$ & $73 \times 89.5$ \\
Compression ratio & 12 \\
Rated power $(\mathrm{kW} / \mathrm{rpm})$ & $110 / 5500$ \\
Max. torque $(\mathrm{N} \cdot \mathrm{m} / \mathrm{rpm})$ & $225 / 1500-4200$ \\
Intake mode & VGT exhaust gas turbocharging \\
Injection pressure & 35 MPa direct-injection system \\
Exhaust manifold & Water-cooled integrated exhaust manifold \\
\hline
\end{tabular}


calibration system, an AVL 602 combustion analyzer, an AVL 735S fuel consumption meter, an AVL 753C temperature controller, an AVL electric dynamometer, and a Horiba exhaust gas analyzer. The composition of the engine test bench is shown in Fig. 1. In the test device, the actuators are controlled via various sensor-aware technologies, with a water temperature sensor used to detect the temperature of the engine cooling water. Intake and exhaust temperature sensors are used to detect the air temperature in the intake pipe and the exhaust pipe. A crankshaft position sensor is used to detect the angle of the engine crankshaft and engine speed. An airflow sensor is used to detect the flow of air into the intake manifold. A knocking sensor is used to detect knocking in the cylinder. An opening throttle sensor is used to detect whether the throttle is open or closed. An oxygen sensor is used to measure excess oxygen in the engine's exhaust gas after combustion occurs. All these sensors transmit signals to the electronic control unit.

\subsection{Test conditions}

For the comparative engine bench test, different engine operating points and load conditions were chosen. The rate of change for the combustion cycle coefficient of variation (COV) was controlled within $3 \%$, the intake air temperature was maintained at $35{ }^{\circ} \mathrm{C}$, the cooling water temperature was maintained at $85 \pm 2{ }^{\circ} \mathrm{C}$, the intake air pressure was maintained at $100 \mathrm{kPa}$, and the fuel oil octane rating was 92 .

\subsection{Research method}

The fuel economy and emission characteristics were compared as the fresh air volume was increased for the EGR combustion technology and diluted combustion technology. Concerning

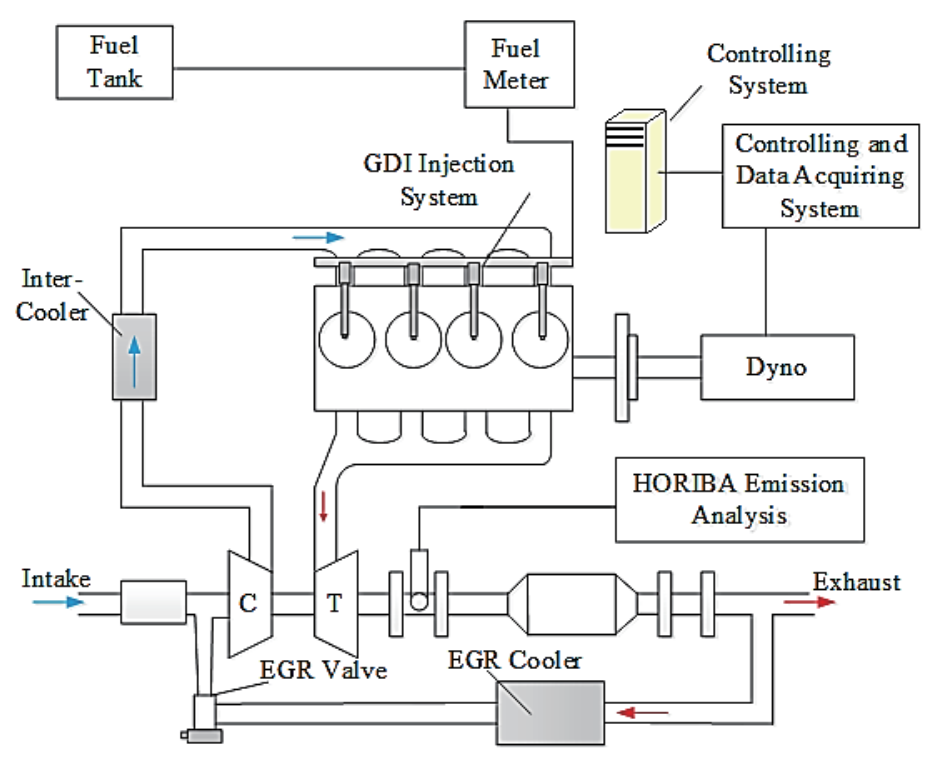

Fig. 1. (Color online) Schematic diagram of the experimental system. 
EGR, we focused on the change in combustion. To achieve this, we controlled parameters such as fuel injection, intake, and ignition advance angle at optimal states and analyzed and recorded the engine's fuel economy and emission characteristics. In the test, the EGR rate was calculated as

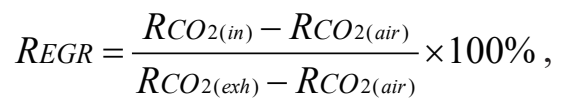

where $R_{E G R}$ is the EGR dilution rate (\%), $R_{\mathrm{CO}_{2}(i n)}$ is the $\mathrm{CO}_{2}$ concentration in the intake pipe after the intercooler (ppm), and $R_{\mathrm{Co}_{2}(e x h)}$ is the $\mathrm{CO}_{2}$ concentration in the exhaust gas after the turbine (ppm).

In lean combustion, the polytropic exponent will change in the cylinder. The fuel economy and emission characteristics were compared under similar operating conditions, i.e., ignition advance angle, intake pressure, and fuel injection pulse width. The dilution degree of lean combustion was measured using excess air with a coefficient of 1 lambda.

The different engine operating points of diluted combustion are shown in Table 2. The original engine was operated in stoichiometric combustion mode and maintained an EGR rate of 0 , and the load characteristics of $5,8,11,14$, and 17 bar were evaluated at an engine speed of $2000 \mathrm{r} / \mathrm{min}$.

In order to compare and analyze the effects of different diluted combustion technologies, we define the following parameters for the combustion process: the top center of engine compression is configured to the $0{ }^{\circ} \mathrm{C}$ crankshaft angle, with MFB10 defined as the point when the heat release reaches $10 \%$ (i.e., the ignition delay period), MFB50 defined as the combustion phase when the heat release reaches $50 \%$, MFB90 defined as the point when the heat release reaches $90 \%$, and MFB10-90 defined as the combustion duration, given by

$$
M F B 10-90=M F B 90-M F B 10 .
$$

Table 2

Experimental conditions and technical parameters of diluted combustion.

\begin{tabular}{cccc}
\hline Engine operating point & Speed/load (r/min/bar) & EGR dilution rate (\%) & Excess air coefficient \\
\hline 1 & $2000 / 5$ & 0 & 0 \\
2 & $2000 / 8$ & 0 & 0 \\
3 & $2000 / 11$ & 0 & 0 \\
4 & $2000 / 14$ & 0 & 0 \\
5 & $2000 / 17$ & 0 & 0 \\
6 & $2000 / 5$ & 0 & 1.40 \\
7 & $2000 / 8$ & 0 & 1.40 \\
8 & $2000 / 11$ & 0 & 1.40 \\
9 & $2000 / 14$ & 0 & 1.35 \\
10 & $2000 / 17$ & 0 & 1.25 \\
11 & $2000 / 5$ & 14 & 1 \\
12 & $2000 / 8$ & 15.5 & 1 \\
13 & $2000 / 11$ & 16 & 1 \\
14 & $2000 / 14$ & 20 & 1 \\
15 & $2000 / 17$ & 16 & 1 \\
\hline
\end{tabular}




\section{Experimental Results and Analysis}

\subsection{Engine fuel economy comparison of different diluted combustion technologies}

The fuel economies of the original engine and the engine with the diluted combustion technologies were evaluated through tests at 5, 8, 11, 14, and 17 bar at an engine speed of $2000 \mathrm{r} / \mathrm{min}$. An engine fuel economy test was also carried out under the same working conditions with different and optimized dilution parameters. The results are shown in Fig. 2. Among the three different combustion technologies, excess air diluted combustion showed the best fuel economy under all conditions, and the fuel consumption of EGR diluted combustion was also significantly less than that of the original engine.

To comprehensively analyze the combustion process and specific fuel consumption trends of the three different combustion technologies, we tested the advanced ignition angle, ignition delay period MFB10, combustion phase MFB50, and combustion duration MFB10-90, as shown in Figs. 3-6, respectively.

Compared with the original combustion engine, the EGR and excess air diluted combustion engines had a lower mixture temperature at the end of compression, which allowed the engines to adopt a more radical ignition angle to obtain better combustion. Figures 3 and 4 show that EGR diluted combustion achieved the most advanced ignition angle and the most significant ignition delay period MFB10, which resulted in the longest combustion phase MFB50 (Figs. 5 and 6), which was beneficial for improving engine fuel economy. However, note that not only the combustion phase MFB50 but also the polytropic exponent affected fuel consumption. After EGR diluted combustion, the engine cylinder's polytropic exponent was smaller than that of the original engine, but after excess air diluted combustion, the polytropic exponent was significantly more extensive than that of the original engine. In this study, the improvement in the engine fuel economy resulting from the increased polytropic exponent was more significant than that achieved by MFB50 optimization alone, so excess air diluted combustion obtained the most outstanding fuel economy. In addition, even though the advanced ignition angle, the delay

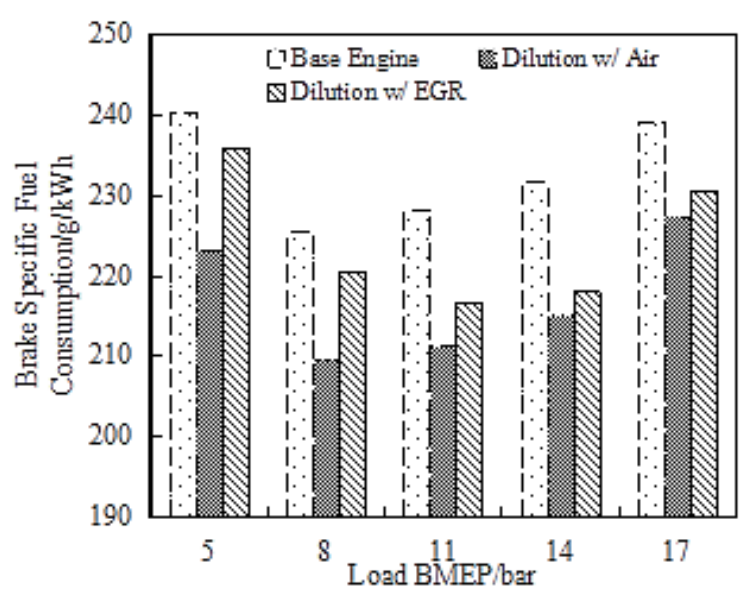

Fig. 2. Specific fuel consumption of engines with different combustion technologies. 


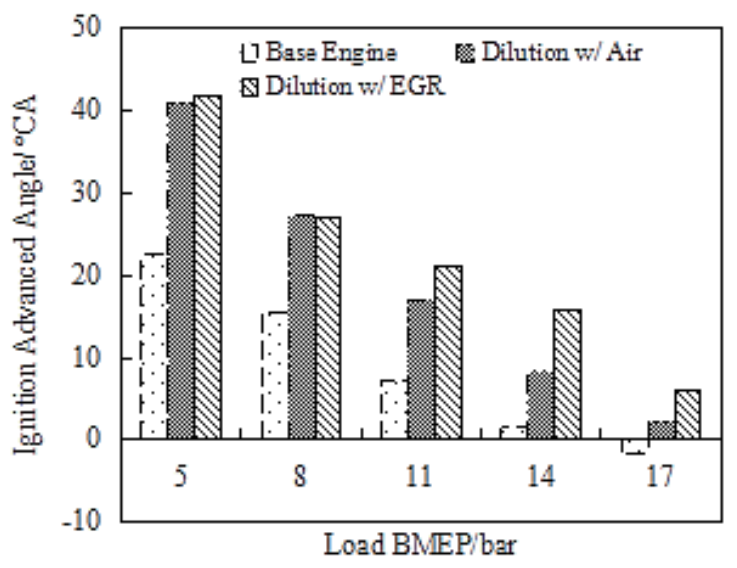

Fig. 3. Ignition advanced angle for different combustion technologies.

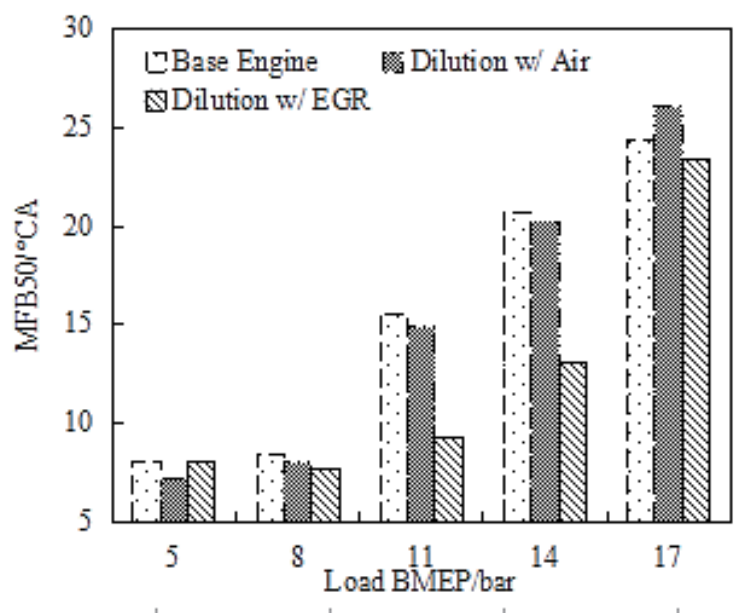

Fig. 5. MFB50 for different combustion technologies.

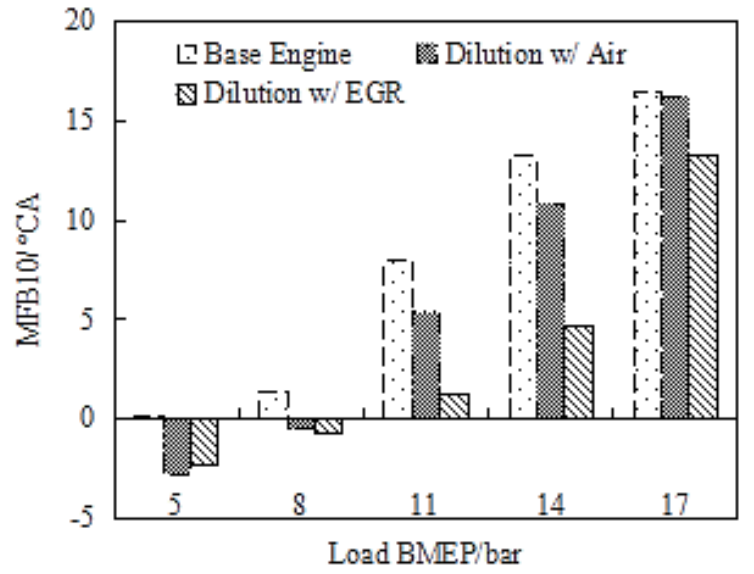

Fig. 4. Ignition delay period MFB10 for different combustion technologies.

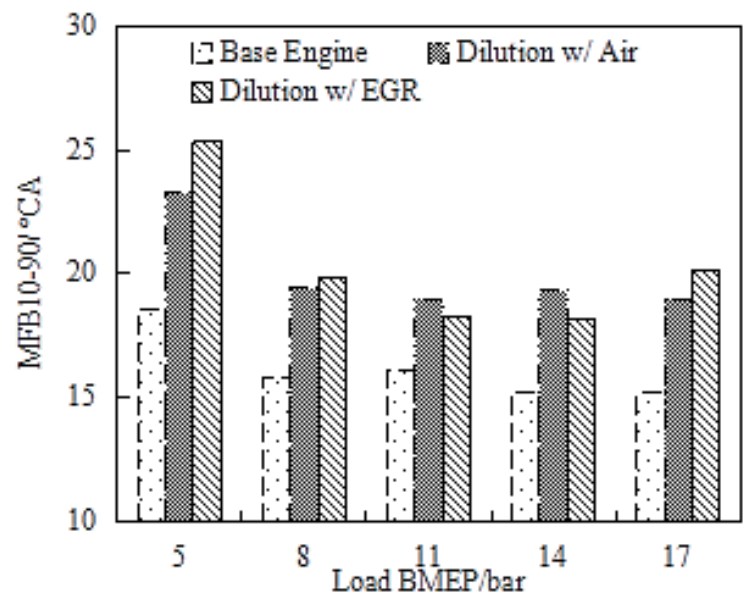

Fig. 6. MFB10-90 for different combustion technologies.

period MFB10, and combustion phase MFB50 of diluted combustion were better than those of the original engine, the combustion duration MFB10-90 was longer than that of the original engine, which showed that the flame speed of diluted combustion was lower than that of the original engine. The combustion duration had little effect on the engine fuel economy.

On the basis of the above analysis, it can be concluded that under the parameters of EGR diluted combustion and excess air diluted combustion adopted in this study, the change in the polytropic exponent played a decisive role in improving the fuel economy. The combustion technology with excess air dilution had the lowest fuel consumption, the EGR dilution technology achieved better fuel economy than the original engine through better combustion, and the combustion duration had a limited effect on engine fuel economy. 


\subsection{Comparison of engine emission characteristics with different dilution parameters}

The emission characteristics of $\mathrm{HC}, \mathrm{CO}$, and $\mathrm{NOx}$ under different loads were examined at the same operating points as those in the above comparative study of engine fuel economy. The results are shown in Figs. 7-9.

It can be seen from Fig. 7 that the HC emission of EGR diluted combustion was higher than that of the original engine and excess air diluted combustion at all operating points when the engine was running at both medium and small loads. At increased loads, the HC emission decreased. The analysis showed three main factors resulting in $\mathrm{HC}$ emission from the engine: the slit effect, incomplete combustion, and a later oxidation process. When EGR diluted combustion technology was tested, the combustion temperature in the cylinder dropped sharply, the flame propagation speed decreased, and the inertia of EGR recycled exhaust gas aggravated the incomplete combustion, resulting in the highest $\mathrm{HC}$ emission. Under small and medium loads, the combustion temperature in the cylinder was relatively low, and the lean mixture increased the $\mathrm{HC}$ emission during incomplete combustion, so the resulting $\mathrm{HC}$ emission was high. With increasing load, the amount of circulating fuel increased, the later oxidation process of HC was much improved, and the oxygen content in the diluted combustion mode was abundant, which significantly promoted the $\mathrm{HC}$ oxidation process, resulting in lower $\mathrm{HC}$ emission. The heat load in the cylinder increased with increasing engine load, which improved the later oxidation process of HCs, which explains why $\mathrm{HC}$ emission decreased with increasing load.

Figure 8 shows the trend of $\mathrm{CO}$ emissions with increasing load for the three different combustion technologies. The $\mathrm{CO}$ emission of excess air diluted combustion was much lower than that of the original engine and EGR diluted combustion. This low CO emission was mainly due to the strong correlation between the $\mathrm{CO}$ emission of the gasoline engine and the excess air coefficient. $\mathrm{CO}$ emission was significantly reduced under oxygen-rich conditions, so the $\mathrm{CO}$ emission for excess air diluted combustion was much lower than that for the original engine and

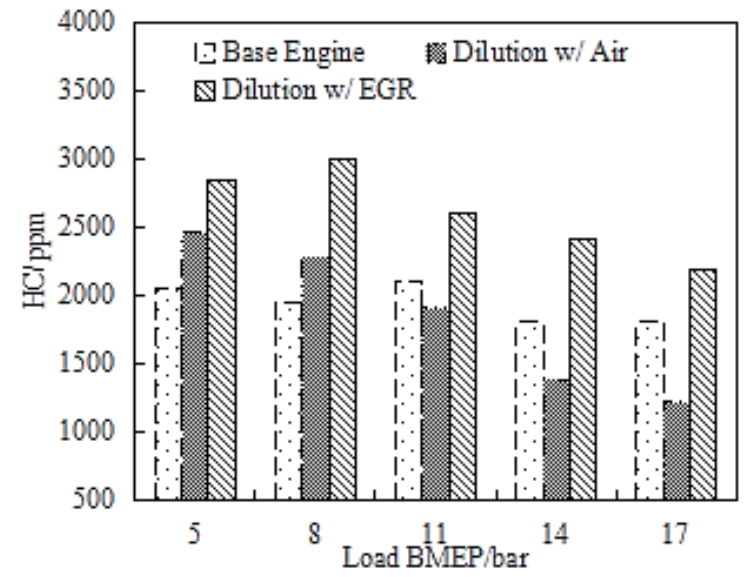

Fig. 7. HC emission of engines with different combustion technologies.

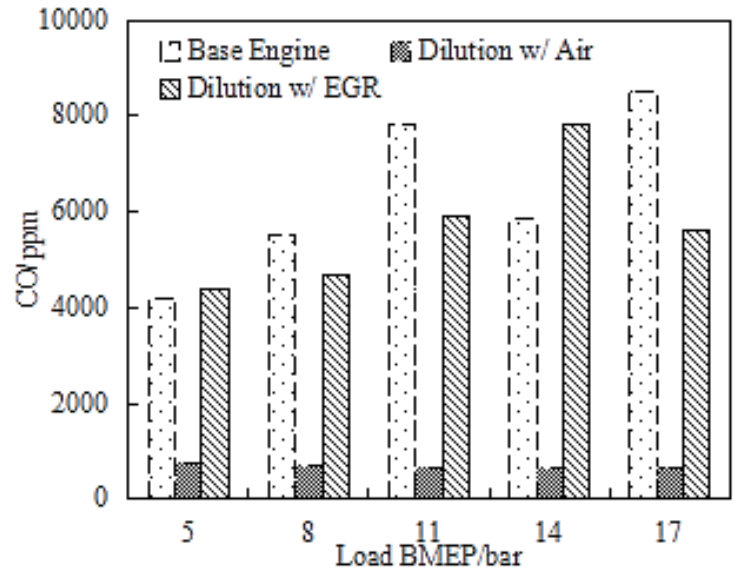

Fig. 8. $\mathrm{CO}$ emission of engines with different combustion technologies. 
EGR diluted combustion. In the EGR diluted combustion and original combustion processes, the stoichiometric air-to-fuel ratio was used, and the $\mathrm{CO}$ emission showed no apparent change with increasing load.

It can be seen from Fig. 9 that, except for the full load condition of $2000 \mathrm{r} / \mathrm{min}$ at $17 \mathrm{bar}$, NOx emission decreased in the order original combustion process $>$ excess air diluted combustion $>$ EGR diluted combustion. NOx generation in a gasoline engine occurs under high-temperature, oxygen-rich, and long-temperature-duration conditions. Changing any of these conditions would directly affect the generation of NOx. Compared with the original engine, the cylinder's combustion temperature was reduced for EGR diluted combustion and excess air diluted combustion, resulting in lower NOx emission. The atmosphere of excess air diluted combustion was more oxidative than that of EGR diluted combustion, which resulted in higher NOx emission. Also, under $2000 \mathrm{r} / \mathrm{min}$ at 17 bar, the engine cylinder's heat load was very high, and the oxygen-rich condition of lean combustion caused its NOx emission to exceed that of the original engine.

The results showed that the engine's fuel economy and emission performances with diluted combustion technology were better than those of the original engine, so diluted combustion technology is worthy of further research. In contrast to fuel vehicles, an electric vehicle has zero emissions in use, although there are waste emissions from battery production. Note that most of the electricity used for Chinese electric vehicles is converted from coal combustion, so the average pollutant emission per passenger in electric vehicles is about three times that of fuel vehicles. If diluted combustion technology was adopted, the average emission of pollutants would decrease. With the current power generation infrastructure in China, the promotion of electric vehicles would reduce NOx pollution but still result in large amounts of CO and HC pollution. When promoting electric vehicles, it is also necessary to transform the current power generation infrastructure and perhaps use fluctuating renewable energy such as wind energy and solar energy to reduce environmental pollution effectively.

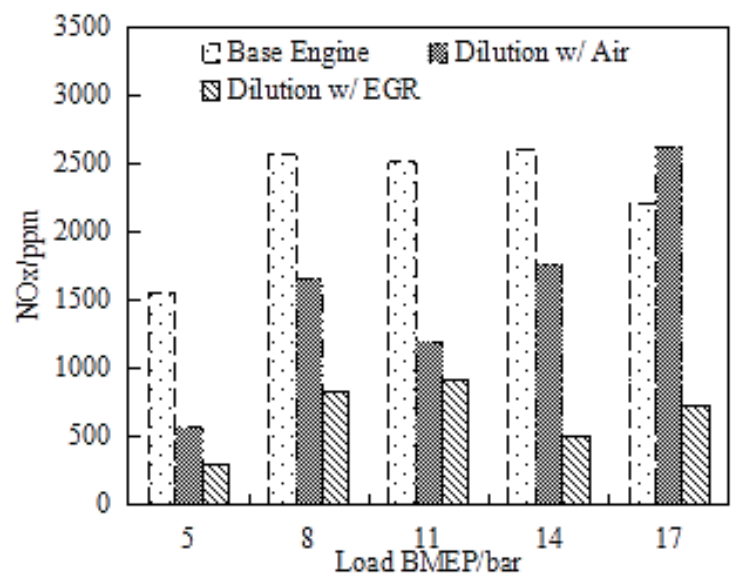

Fig. 9. NOx emission of engines with different combustion technologies. 


\section{Conclusion}

(1) We tested the use of excessive air diluted combustion and EGR diluted combustion technology using sensors in the engine and observed the intelligent control of the differences between the intake and exhaust volumes of the original engine. Fuel economy tests showed that the fuel consumption of excess air diluted combustion and EGR diluted combustion was better than that of the original engine, and that excess air diluted combustion produced the least emissions.

(2) In this study, we observed the effect of the polytropic exponent in an engine cylinder and concluded that it directly affects fuel consumption. We also observed that improved combustion significantly reduces fuel consumption and that the combustion duration has little impact on the engine fuel economy.

(3) The HC emission of EGR diluted combustion was higher than that of excess air diluted combustion and the original engine at medium and small loads but lower than that of the original engine at large loads. The $\mathrm{CO}$ emission of excess air diluted combustion was much lower than that of EGR diluted combustion and the original engine. In addition, it should be noted that at $2000 \mathrm{r} / \mathrm{min}$ with a $17 \mathrm{bar}$ full load, NOx emissions decreased for all three combustion technologies.

(4) Electric vehicles have zero emissions in their use, but the energy sources of electric vehicles in China are produced from thermal power generation, which has high $\mathrm{CO}$ and $\mathrm{HC}$ emissions. The resulting overall pollution caused by electric vehicles is currently more significant than that produced by diluted combustion engines. In future vehicle development, industries must adopt newer engine technologies, change the energy production infrastructure, and adopt fluctuating renewable energy sources such as wind energy and solar energy to reduce air pollution.

\section{Acknowledgments}

This work was supported by the Open Fund Project of Chongqing Engineering Technology Research Center for Light Alloy and Processing (No. GCZX201901), the Science and Technology Research Program of Chongqing Education Commission of China (No. KJQN201901201), the Science and Technology Research Program of Chongqing Municipal Education Commission (No. KJQN202001228), and Chongqing Engineering Research Center for Advanced Intelligent Manufacturing Technology (No. ZNZZXDJS 202009).

\section{References}

1 J. Zhao: Appl. Energ. 185 (2017) 300. https://doi.org/10.1016/j.apenergy.2016.10.063

2 H. C. Liu, M. Yang, M. Zhou, and G. Tian: IEEE. T. Intel. Transp. 20 (2019) 362. https://doi.org/10.1109/ TITS.2018.2815680

3 H. Zhao and N. Li: Energies 9 (2016) 270. https://doi.org/10.3390/en9040270

4 A. R. Holdway, A. R. Williams, O. R. Inderwildi, and D. A. King: Energ. Environ. Sci. 3 (2010) 1825. https:// doi.org/10.1039/C0EE00031K

5 R. T. Doucette and M. D. Mcculloch: Energy 88 (2011) 2315. https://doi.org/10.1016/j.apenergy.2011.01.045 
6 J. Su, M. Xu, T. Li, Y. Gao, and J. Wang: Energ. Convers. Manage. 78 (2014) 65. https://doi.org/10.1016/j. enconman.2013.10.041

7 M. Pontoppidan, G. Gaviani, G. Bella, A. de Maio, and V. Rocco: SAE Tech. Paper. (1999) 01-0173. https://doi. org/10.4271/1999-01-0173

8 J. B Heywood: Internal Combustion Engine Fundamentals (McGraw-Hill Companies, New York, 1988)

9 J. Kodavasal, G. A. Lavoie, D. N. Assanis, and J. B. Martz: Combust. Flame. 162 (2015) 451. https://doi. org/10.1016/j.combustflame.2014.07.026

10 L. Liu, Z. Li, S. Liu, and B. Shen: Mech. Syst. Signal Process. 87 (2016) 195. https://doi.org/10.1016/j. ymssp.2015.12.029

11 S. Onishi , S. H. Jo, K. Shoda, P. D. Jo, and S. Kato: SAE Trans. 88 (1979) 1851. https://www.jstor.org/ stable/44658187

12 W. Li, Z. Liu, Z. Wang, and Y. Xu: Energ. Convers. Manage. 88 (2014)1041. https://doi.org/10.1016/j. enconman.2014.09.051

13 D. Jung, K. Sasaki , K. Sugata , M. Matsuda, T. Yokomori, and N. Iida: SAE Tech. Paper (2017) 01. https://doi. org/10.4271/2017-01-0677

14 D. Ganesh and G. Nagarajan: Energy 35 (2010) 148. https://doi.org/10.1016/j.energy.2009.09.005

15 S. S. Nathan, J. M. Mallikarjuna, and A. Ramesh: Fuel 89 (2010) 515. https://doi.org/10.1016/j.fuel.2009.08.032

16 M. Yao, Z. Chen, Z. Zheng, B Zhang, and Y Xing: Fuel 85 (2006) 2046. https://doi.org/10.1016/j. fuel.2006.03.016

\section{About the Authors}

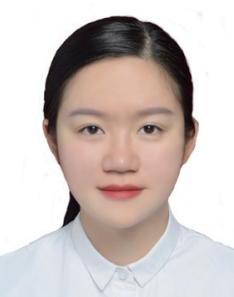

Juan Yan received her B.S. degree from Jiangxi Agricultural University, China, and her M.S. degree from Jiangxi Agricultural University, China, in 2011 and 2014, respectively. She joined Chongqing Three Gorges University in 2014, where she is currently a lecturer. Her research interests include big data analysis of electric vehicles and combustion characteristics of engines. (A58238735@Outlook.com)

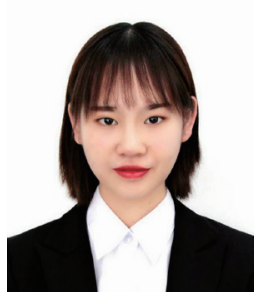

Le Gao received her B.S. degree from Sichuan University of Science and Engineering, China, and her M.S. degree from Chongqing Three Gorges University, China in 2019. She is currently a graduate student studying at Chongqing Three Gorges University. Her research interests are large-scale electric vehicle network access models and big data analysis.

(ag11509@163.com)

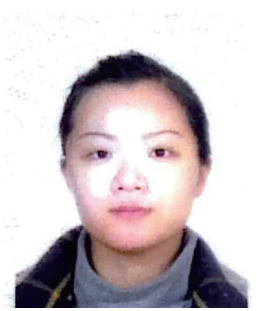

Nina Dai received her B.S. and M.S. degrees from Central China Normal University, China, in 2005 and 2008, respectively. She is now working at Chongqing Three Gorges University as an associate professor. Her research interests are electric vehicle batteries and engineering applications of modern communication technology. (Y406591408@Outlook.com) 


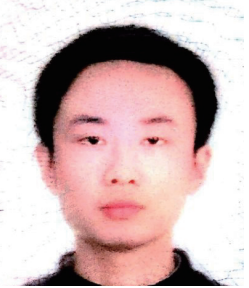

Li Cai received his B.S. degree from China University of Mining and Technology, China, and his M.S. degree from Chongqing University, China, in 2007 and 2010, respectively. He is now working at Chongqing Three Gorges University as a professor. His research interests are electric vehicle batteries and control and communication technologies. (20040001@sanxiau.edu.cn)

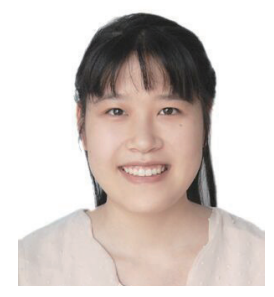

Jialan Shi received her B.S. degree from Nanjing University of Posts and Telecommunications, China. She is a graduate student studying at Chongqing Three Gorges University, China in 2020. Her research interests are electricity information collection and electricity metering. (chunshen01@126.com)

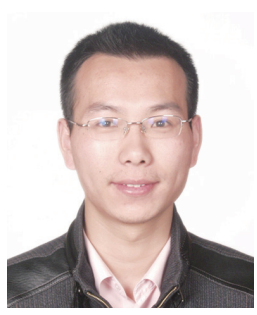

Qingshan Xu received his B.S. and Ph.D. degrees from Southeast University, China, and his M.S. degree from Hohai University, China. He works as a professor at Southeast University, where he is also a doctoral supervisor. His research interests are new-energy power generation technology and load resource dispatching. (xuqingshan@seu.edu.cn)

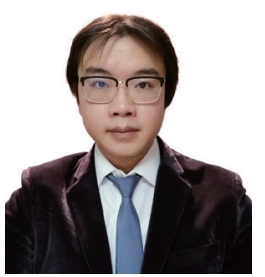

Christopher Chun Ki Chan has been an assistant professor at Chaoyang University of Technology, Taiwan, since 2019. He is an IEEE member and an active reviewer for computer science journals and conferences such as TEMS. He earned his M.S. and Ph.D. degrees from the Department of Computer Science, Ryerson University, Canada. His research interests include deep learning technology and Industry 4.0 applications.

(christopherckchan@cyut.edu.tw) 